Acta Crystallographica Section F

Structural Biology

and Crystallization

Communications

ISSN 1744-3091

\author{
Wei Wang, ${ }^{a}$ Lei Wei, ${ }^{a}$ Anqi \\ Yang, ${ }^{a}$ Teng He, ${ }^{a}$ K. Y. Yuen, \\ Cheng Chen ${ }^{\mathrm{a} *}$ and Zihe Rao $^{\mathrm{a}, \mathrm{c}}$
}

${ }^{\text {a}}$ Tsinghua-Nankai-IBP Joint Research Group for Structural Biology, Tsinghua University, Beijing 100084, People's Republic of China,

baboratory of Avian Medicine, College of Veterinary Medicine, South China Agricultural University, Guangzhou 510642, People's Republic of China, and 'National Laboratory of Macromolecules, Institute of Biophysics, Chinese Academy of Science, Beijing 100101, People's Republic of China

Correspondence e-mail:

chench@mail.xtal.tsinghua.edu.cn

Received 2 December 2008

Accepted 15 April 2009

\section{Expression, crystallization and preliminary crystallographic study of human coronavirus HKU1 nonstructural protein 9}

Human coronavirus HKU1 (HCoV-HKU1) belongs to coronavirus group II and encodes 16 nonstructural proteins (nsps) which mediate genome replication and transcription. Among these nsps, nsp9 has been shown to possess singlestranded DNA/RNA-binding properties. The gene that encodes HCoV-HKU1 nsp9 was cloned and expressed in Escherichia coli and the protein was subjected to crystallization trials. The crystals diffracted to $2.7 \AA$ resolution and belonged to space group $P 2{ }_{1} 2{ }_{1} 2$, with unit-cell parameters $a=83.5, b=88.4, c=31.2 \AA$, $\alpha=\beta=\gamma=90^{\circ}$ and two molecules per asymmetric unit.

\section{Introduction}

Since the global outbreak of SARS coronavirus in 2003, which caused 750 deaths in over 8000 patients, several novel human coronaviruses (HCoVs) have been discovered, one of which is human coronavirus HKU1 (HCoV-HKU1; Woo, Huang et al., 2005). HKU1 is a member of the genus Coronavirus, which can be classified into three distinct groups (Spaan \& Cavanagh, 2004). Like SARS, HKU1 also belongs to coronavirus group II and infects humans (Gerna et al., 2007). Patients infected by HKU1 have been reported worldwide, including in Korea (Choi et al., 2006), North America (Esper et al., 2006), Australia (Sloots et al., 2006) and Europe (Bosis et al., 2007) and often exhibit self-limiting syndromes in the lower respiratory tract (Zhao et al., 2008). Genome-sequencing research showed that HKU1 shares high sequence homology with mouse hepatitis virus (MHV; Woo, Huang et al., 2005), another group II coronavirus.

The HKU1 genome is a single-stranded positive-sense polyadenylated RNA of 29926 nucleotides. In common with other coronaviruses, this genome contains two large ORFs (ORFs 1a and 1b) that are required for RNA transcription and genome replication and that are processed into 16 nonstructural proteins by virusencoded proteinases (Snijder et al., 2003; Prentice et al., 2004; Woo, Lau et al., 2005). Nsp9 has been shown to be essential for viral RNA synthesis and replication based on deletion experiments in MHV (Deming et al., 2007). The presence of two molecules of nsp9 per asymmetric unit may indicate that the protein functions as a dimer, as is the case for SARS-CoV nsp9 (Campanacci et al., 2003). Based on available structural data, nsp9 has been proposed to possess the function of stabilizing nascent nucleic acids during RNA synthesis and participating in such base-pairing-driven processes based on its single-stranded RNA-binding properties (Egloff et al., 2004).

\section{Expression and purification}

The cDNA encoding HCoV-HKU1 nsp9 was provided by Professor K. Y. Yuen (Department of Microbiology, Hong Kong University, HKSAR, China). The gene encoding HKU1 nsp9 (corresponding to Asn4211-Gln4320, where the numbering is that of the entire polyprotein) was amplified by the PCR method using forward and reverse primers 5'-CGGGATCCAATAATGAGTTGATGCCT-3' and 5'-CCGCTCGAGTTACTGCAATCTAATTGTTG- ${ }^{\prime}$, respectively, and then inserted between the Bam HI and XhoI sites of the pGEX-6p-1 plasmid. After verifying the sequence, the recombinant plasmid was 
transformed into Escherichia coli BL21 (DE3). Cultures were grown in LB medium containing $0.1 \mathrm{mg} \mathrm{m}^{-1}$ ampicillin at $310 \mathrm{~K}$ until the optical density at $600 \mathrm{~nm}\left(\mathrm{OD}_{600}\right)$ reached $0.6 .0 .5 \mathrm{~m} M$ isopropyl $\beta$-D1-thiogalactopyranoside (IPTG) was added and the cultures were induced to express HKU1 nsp9 at $289 \mathrm{~K}$ for $16 \mathrm{~h}$. Centrifugation was used to harvest the cells and the bacterial pellets were resuspended in PBS (140 m $M \mathrm{NaCl}, 10 \mathrm{~m} M \mathrm{Na}_{2} \mathrm{HPO}_{4}, 2.7 \mathrm{~m} M \mathrm{KCl}, 1.8 \mathrm{~m} M \mathrm{KH}_{2} \mathrm{PO}_{4}$ $\mathrm{pH}$ 7.3) supplemented with $1 \mathrm{~m} M$ DTT. After sonication at $277 \mathrm{~K}$, the lysate was centrifuged at $12000 \mathrm{~g}$ for $50 \mathrm{~min}$ at $277 \mathrm{~K}$ and the precipitate was discarded. The supernatant was loaded onto a GSTglutathione affinity column (Pharmacia). The fusion protein was then cleaved on the column by GST-rhinovirus $3 \mathrm{C}$ protease at $277 \mathrm{~K}$ for $18 \mathrm{~h}$; five additional residues (GPLGS) were left at the N-terminus of HKU1 nsp9. The cleavage buffer of the protease was PBS and the ratio of protease to protein was approximately 1:50. Thermo iCON concentrators were used to concentrate the protein. After concentration using a Thermo Centra-CL3R, a Superdex 75 column (GE

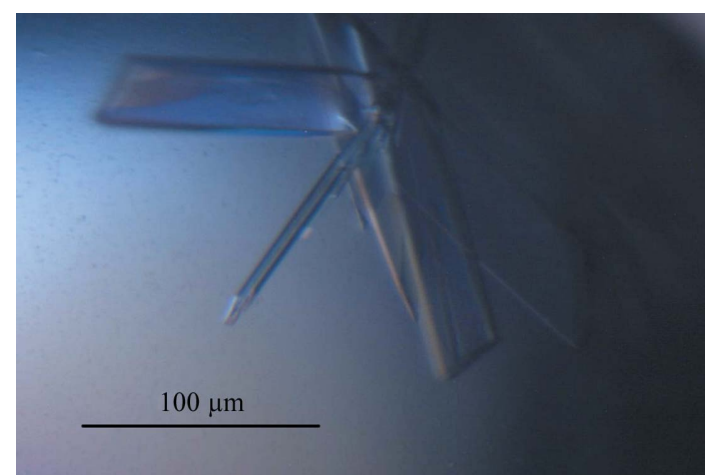

Figure 1

Typical crystals of HKU1 nsp9 grown by the hanging-drop method in $0.1 M$ sodium citrate tribasic dehydrate $\mathrm{pH} 5.6,20 \%(v / v)$ 2-propanol, $20 \%(w / v)$ polyethylene glycol 4000. Typical crystal dimensions are $0.3 \times 0.03 \times 0.04 \mathrm{~mm}$.
Healthcare) was used to purify the HKU1 nsp9 in a buffer containing $20 \mathrm{~m} M$ MES, $150 \mathrm{~m} M \mathrm{NaCl} \mathrm{pH}$ 6.0. Typical yields were $3 \mathrm{mg}$ of purified protein per litre of bacterial culture.

\section{Crystallization}

After purification, the HKU1 nsp9 protein was concentrated to $25 \mathrm{mg} \mathrm{ml}^{-1}$ in a buffer containing $150 \mathrm{~m} M \mathrm{NaCl}, 20 \mathrm{~m} M \mathrm{MES} \mathrm{pH} 6.0$. Crystal Screen reagent kits (Hampton Research) were used to screen for conditions for crystallization. We performed crystal screening using the vapour-diffusion technique at $291 \mathrm{~K}$ in 16-well crystallization plates. $1.0 \mu \mathrm{l}$ protein solution was mixed with $1.0 \mu \mathrm{l}$ reservoir solution and then left to reach equilibrium while hanging over $400 \mu \mathrm{l}$ reservoir solution. Initial crystals of HKU1 nsp9 were obtained using condition No. 40 from Hampton Research Crystal Screen 1, which contained $0.1 \mathrm{M}$ sodium citrate tribasic dehydrate $\mathrm{pH} 5.6,20 \%(\mathrm{v} / \mathrm{v})$ 2-propanol, 20\%(w/v) polyethylene glycol 4000. The optimized condition contained $0.12 \mathrm{M}$ sodium citrate tribasic dehydrate $\mathrm{pH}$ 5.6, $20 \%(v / v)$ 2-propanol, 25\%(w/v) polyethylene glycol 4000 (Fig. 1).

\section{Data collection and processing}

The crystal was directly mounted in a nylon loop and flash-cooled in a nitrogen stream at $100 \mathrm{~K}$ using an Oxford Cryosystems cryostream. The diffraction data were collected in-house on a Rigaku $\mathrm{Cu} K \alpha$ rotating-anode X-ray generator (MM-007) at $40 \mathrm{kV}$ and $20 \mathrm{~mA}$ $(1.5418 \AA)$ with a Rigaku R-AXIS IV ${ }^{++}$image-plate detector. Data were processed, integrated, scaled and merged using the $H K L-2000$ programs DENZO and SCALEPACK (Otwinowski \& Minor, 1997). The crystals diffracted to $2.7 \AA$ resolution (Fig. 2). They belonged to space group $P 2{ }_{1} 2{ }_{1} 2$, with unit-cell parameters $a=83.5, b=88.4$, $c=31.2 \AA, \alpha=\beta=\gamma=90^{\circ}$. Based on the molecular weight of the monomer, the Matthews coefficient (Matthews, 1968) was calculated

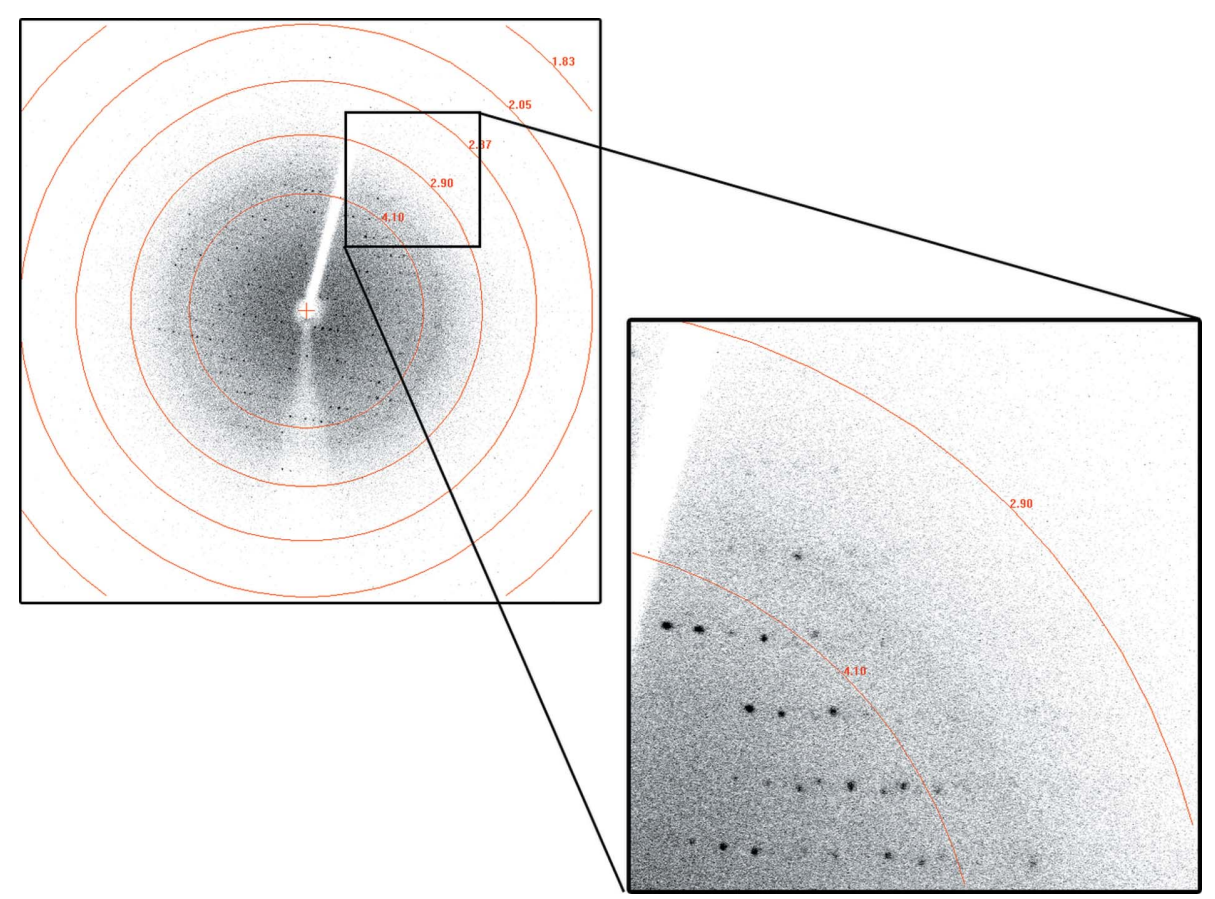

Figure 2

A typical diffraction pattern of an HKU1 nsp9 crystal collected on a Rigaku R-AXIS IV ${ }^{++}$image-plate detector. 


\section{crystallization communications}

Table 1

Data-collection and processing statistics.

Values in parentheses are for the highest resolution shell.

\begin{tabular}{ll}
\hline Wavelength $(\AA)$ & 1.5418 \\
Resolution $(\AA)$ & $50.0-2.7(2.8-2.7)$ \\
Space group & $P 2_{1} 2_{1} 2$ \\
Unit-cell parameters $\left(\AA{ }^{\circ}{ }^{\circ}\right)$ & \multicolumn{1}{c}{$\alpha=83.5, b=88.4, c=31.2}$, \\
& $7.9(43.6)$ \\
$R_{\text {merge }} \dagger(\%)$ & 2.35 \\
Matthews coefficient $\left(\AA^{3} \mathrm{Da}^{-1}\right)$ & 47.77 \\
Solvent content $(\%)$ & $17.4(2.1)$ \\
Average $I / \sigma(I)$ & $97.1(91.0)$ \\
Completeness $(\%)$ & $5.5(4.3)$ \\
Redundancy & 37325 \\
No. of observed reflections & 6738 \\
No. of unique reflections & 2 \\
Molecules per ASU &
\end{tabular}

$\dagger R_{\text {merge }}=\sum_{h k l} \sum_{i}\left|I_{i}(h k l)-\langle I(h k l)\rangle\right| / \sum_{h k l} \sum_{i} I_{i}(h k l)$, where $I_{i}(h k l)$ is an individual intensity measurement and $\langle I(h k l)\rangle$ is the average intensity for all the reflections $i$.

to be $2.35 \AA^{3} \mathrm{Da}^{-1}$ and the solvent content was $47.77 \%$, assuming the presence of two molecules per asymmetric unit. Data-collection statistics are shown in Table 1. Further structural and functional analysis of HKU1 nsp9 will reveal the conserved structural and functional aspects that are common to the different groups that make up the coronavirus family.

This work was supported by Project 973 of the Ministry of Science and Technology of China (grant No. 2006CB914301) and the National Natural Science Foundation of China (NSFC; grant Nos. 30221003 and 30730022).

\section{References}

Bosis, S., Esposito, S., Niesters, H. G., Tremolati, E., Pas, S., Principi, N. \& Osterhaus, A. D. (2007). J. Clin. Virol. 38, 251-253.

Campanacci, V., Egloff, M.-P., Longhi, S., Ferron, F., Rancurel, C., Salomoni, A., Durousseau, C., Tocque, F., Brémond, N., Dobbe, J. C., Snijder, E. J., Canard, B. \& Cambillau, C. (2003). Acta Cryst. D59, 1628-1631.

Choi, E. H., Lee, H. J., Kim, S. J., Eun, B. W., Kim, N. H., Lee, J. A., Lee, J. H., Song, E. K., Kim, S. H., Park, J. Y. \& Sung, J. Y. (2006). Clin. Infect. Dis. 43, $585-592$.

Deming, D. J., Graham, R. L., Denison, M. R. \& Bar, R. S. (2007). J. Virol. 81, 10280-10291.

Egloff, M.-P., Ferron, F., Campanacci, V., Longhi, S., Rancurel, C., Dutartre, H., Snijder, E. J., Gorbalenya, A. E., Cambillau, C. \& Canard, B. (2004). Proc. Natl Acad. Sci. USA, 101, 3792-3796.

Esper, F., Weibel, C., Ferguson, D., Landry, M. L. \& Kahn, J. S. (2006). Emerg. Infect. Dis. 12, 775-779.

Gerna, G., Percivalle, E., Sarasini, A., Campanini, G., Piralla, A., Rovida, F., Genini, E., Marchi, A. \& Baldanti, F. (2007). J. Clin. Virol. 38, 244-250.

Matthews, B. W. (1968). J. Mol. Biol. 33, 491-497.

Otwinowski, Z. \& Minor, W. (1997). Methods Enzymol. 276, 307-326.

Prentice, E., McAuliffe, J., Lu, X., Subbarao, K. \& Denison, M. R. (2004). J. Virol. 78, 9977-9986.

Sloots, T. P., McErlean, P., Speicher, D. J., Arden, K. E., Nissen, M. D. \& Mackay, I. M. (2006). J. Clin. Virol. 35, 99-102.

Snijder, E. J., Bredenbeek, P. J., Dobbe, J. C., Thiel, V., Ziebuhr, J., Poon, L. L. M., Guan, Y., Rozanov, M., Spaan, W. J. M. \& Gorbalenya, A. E. (2003). J. Mol. Biol. 331, 991-1004.

Spaan, W. J. M. \& Cavanagh, D. (2004). Virus Taxonomy. VIIIth Report of the ICTV, pp. 945-962. London: Elsevier/Academic Press.

Woo, P. C., Huang, Y., Lau, S. K., Tsoi, H. W. \& Yuen, K. Y. (2005). Microbiol. Immunol. 49, 899-908.

Woo, P. C., Lau, S. K., Chu, C. M., Chan, K. H., Tsoi, H. W., Huang, Y., Wong, B. H., Poon, R. W., Cai, J. J., Luk, W. K., Poon, L. L., Wong, S. S., Guan, Y., Peiris, J. S. \& Yuen, K. Y. (2005). J. Virol. 79, 884-895.

Zhao, Q., Li, S., Xue, F., Zou, Y., Chen, C., Bartlam, M. \& Rao, Z. (2008). J. Virol. 82, 8647-8655. 